\title{
Thermotropic Liquid-Crystalline Polymers Having Five-Membered Heterocycles as Mesogens V. Relationship between Polymer Structure and Thermotropic Liquid-Crystallinity in Semi-Rigid Polyesters Composed of Twin 2-Phenyl-1,3,4-thiadiazoles Having Central Aliphatic Chains
}

\author{
Moriyuki Sato, Tomoaki Yoshinaga, and Naoyuki KoIDE* \\ Department of Material Science, Faculty of Science and Engineering, Shimane University, \\ 1060 Nishikawatsu, Matsue-shi, Shimane 690-8504, Japan \\ ${ }^{*}$ Department of Chemistry, Faculty of Science, Science University of Tokyo, 1-3 Kagurazaka, \\ Shinjuku-ku, Tokyo 162-8602, Japan
}

(Received February 7, 2000; Accepted May 1, 2000)

\begin{abstract}
Semi-rigid polyesters based on twin biphenyl analogues of 1,3,4-thiadiazole (2-phenyl-1,3,4thiadiazoles) with hepta- and octamethylene chains in the central part were synthesized by melt polycondensation of bismethyl ester derivatives of twin 2-phenyl-1,3,4-thiadiazole with $\alpha, \omega$-alkylenediols and dioxydialcohol derivatives of biphenyl. The relationship between polymer structure and thermotropic liquid-crystallinity (LC) was investigated by differential scanning calorimetry (DSC), polarizing microscope observations, miscibility tests and temperature-dependent $\mathrm{X}$-ray analysis. All the polymers derived from $\alpha, \omega$-alkylenediols appeared to form enantiotropic or monotropic nematic phase independent of the lengths of aliphatic chains. Among the polyesters containing the biphenyl unit, most polymers with octamethylene segment between the twin 2-phenyl-1,3,4-thiadiazoles showed the nematic phase, but polymers composed of the twin biphenyl analogue having the central heptamethylene chain had no LC melts.

KEY WORDS Semi-Rigid Polyester / 2-Phenyl-1,3,4-thiadiazole/ Melt Polycondensation / Bismethyl Ester Derivative/Liquid-Crystallinity/Nematic Phase/Differential Scanning Calorimetry Measurement /
\end{abstract}

A terphenyl analogue of 1,3,4-thiadiazole (2,5diphenyl-1,3,4-thiadiazole), a five-membered heterocyclic unit containing sulfur and nitrogen atoms, is a calamitic mesogen. ${ }^{1}$ Derivatives composed of mesogen with flexible chains on both sides, twin terphenyl analogues of the 1,3,4-thiadiazole having alkylenedioxy segments in the center ${ }^{2-5}$ and main- ${ }^{6-8}$ or side-chain ${ }^{9}$ polymers containing the mesogen form nematic and smectic mesophases in spite of its bent molecular structure. ${ }^{2,10-12}$ Our previous articles described that twin 2,5-diphenyl1,3,4-thiadiazole derivatives linking an octamethylenedioxy chain to the center ${ }^{5}$ have stable nematic and smectic phases. Side-chain polymers with the 2,5diphenyl-1,3,4-thiadiazole as a mesogen represent cholesteric and chiral smectic $\mathrm{C}^{*}$ phases. ${ }^{9}$ Enantiotropic thermotropic liquid-crystalline (LC) phases emerge in semi-rigid polyesters derived from diacylchloride of the 2,5-diphenyl-1,3,4-thiadiazole and aliphatic diols, ${ }^{8}$ although wholly aromatic polyesters consisting of calamitic mesogen have no LC melts. ${ }^{13}$

Biphenyl analogues of 1,3,4-thiadiazole (2-phenyl1,3,4-thiadiazoles) have the monotropic smectic A phase, ${ }^{1,14,15}$ although LC temperature range was narrow. ${ }^{2}$ In recent years, Tschierske et al. found that homoand heterotrimeric or tetrameric derivatives with the 2phenyl-1,3,4-thiadiazole ring linked to central flexible chains show the smectic C phase. ${ }^{14,15}$ Thermotropic LC phases appear in semi-rigid LC polyesters based on twin biphenyl analogue of 1,3,4-thiadiazole having decamethylene chain in the central part. ${ }^{16}$ The polymer with octamethylene spacer displayed the monotropic nematic phase and those having decamethylene and dodecamethylene chains showed enantiotropic smectic phases, but LC temperature range was narrow.
The present work describes the synthesis of various semi-rigid polyesters (7) and (8) based on twin biphenyl analogues of 1,3,4-thiadiazole (2-phenyl-1,3,4-thiadiazoles) with central hepta- and octamethylene chains by melt polycondensation using $\alpha, \omega$-alkylenediols (5) or dioxydialcohol derivatives of biphenyl $\left(\omega, \omega^{\prime}-\left(4,4^{\prime}\right.\right.$-biphenylenedioxy)dialcohols) (6) as monomers and discusses the relationship between polymer structure and LC properties for main-chain polymers containing fivemembered heterocyclic moiety as mesogen. The latter (8) is expected to have wider LC temperature range than previously reported semi-rigid LC polyesters, ${ }^{16}$ because they contain the biphenyl unit, a well-known mesogen, in the main chain.

\section{EXPERIMENTAL}

\section{Materials}

1-Chloroformyl-4-methoxycarbonylbenzene (1), azelaic dihydrazide (2a), sebacic dihydrazide (2b), Lawesson's reagent, $N, N$-dimethylformamide (DMF), 1,4-dioxane, triethylamine, $\omega$-halogenoalcohols (6-chloro-1-hexanol, 8-bromo-1-octanol, 10-bromo-1-decanol and 11-bromo-1undecanol) and 4,4'-dihydroxybiphenyl were used without further purification. $\alpha, \omega$-Alkylenediols (5) $(1,8$ octandiol (5a), 1,9-nonandiol (5b), 1,10-decandiol (5c) and 1,12-dodecandiol (5d)) were used after recrystallization from methanol. $\omega, \omega^{\prime}-\left(4,4^{\prime}\right.$-Biphenylenedioxy $)$ dialcohols $(6 \mathrm{a}-\mathrm{d})$ were synthesized from 4,4'-dihydroxybiphenyl and $\omega$-halogenoalcohols in DMF in the presence of potassium carbonate according to the reported methods. ${ }^{17-22}$ 


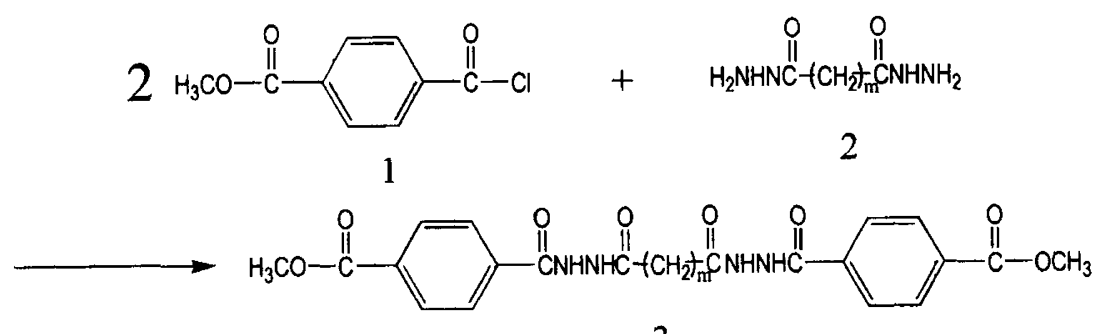

3

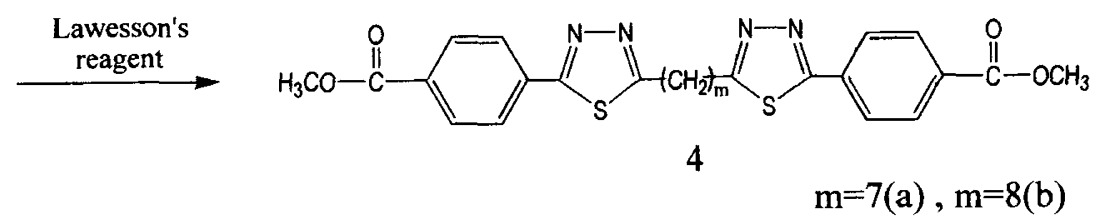

Scheme 1.

\section{Synthesis of Monomers 4}

1,8-Bis[5-(4-methoxycarbonylphenyl)-1,3,4-thiadiazol2-ylloctane (4b). 1-Chloroformyl-4-methoxycarbonylbenzene (1) $(0.06 \mathrm{~mol}, 11.92 \mathrm{~g})$ was dissolved in DMF $(120 \mathrm{~mL})$. Sebacic dihydrazide $(2 \mathrm{~b})(m=8)(0.03 \mathrm{~mol}$, $6.91 \mathrm{~g})$ was added to the solution cooled in an ice-water bath in the presence of triethylamine $(0.06 \mathrm{~mol}, 6.06 \mathrm{~g})$. The mixture was stirred for $1 \mathrm{~h}$ below $10^{\circ} \mathrm{C}$ and for $12 \mathrm{~h}$ at room temperature and then refluxed at $80^{\circ} \mathrm{C}$ for $7 \mathrm{~h}$ and poured into water to precipitate the intermediate dihydrazide $(3 \mathrm{~b})$. The intermediate $(3 \mathrm{~b})$ was collected by filtration, washed throughly with water and acetone and dried at $60^{\circ} \mathrm{C}$ for one day. Yield: $43 \%$. Lawesson's reagent $(26.2 \mathrm{mmol}, 10.06 \mathrm{~g})$ was added to the intermediate bishydrazide $(3 \mathrm{~b})(10.8 \mathrm{mmol}, 6.01 \mathrm{~g})$ in 1,4-dioxane $(150 \mathrm{~mL})$ at $50^{\circ} \mathrm{C}$ and the mixture was stirred under reflux for $10 \mathrm{~h}$. A light brown solid precipitated during cyclodehydration. After the reaction, the precipitate was filtered off, washed with aqueous $0.5 \mathrm{M} \mathrm{NaOH}$ solution $(300 \mathrm{~mL})$, water and methanol. The resulting compound (4b) was recrystallized from DMF twice and dried at $60^{\circ} \mathrm{C}$ for one day in vacuo. Yield: $65 \%$, m.p.: $222-225^{\circ} \mathrm{C}$.

$\mathrm{C}_{28} \mathrm{H}_{30} \mathrm{~N}_{4} \mathrm{O}_{4} \mathrm{~S}_{2}$ (550.7) Calc. C: $61.09 \%, \mathrm{H}: 5.45 \%, \mathrm{~N}:$ 10.18\%; Found C: $60.91 \%, \mathrm{H}: 5.46 \%$, N: $10.22 \%$. FT-IR (KBr disk): $1715\left(v_{\mathrm{C}=0}\right), 1406$ (1,3,4-thiadiazole), 1276 $\left(v_{\mathrm{C}-\mathrm{O}-\mathrm{C}}\right), 2940,2905$, and $2846 \mathrm{~cm}^{-1}\left(v_{\mathrm{C}-\mathrm{H}}\right),{ }^{13} \mathrm{C} \mathrm{NMR}$ (trifluoroacetic acid (TFAA)/CDCl $3=3 / 1$ in volume): $181.1(\mathrm{C}=\mathrm{O}), \quad 170.5$ (2-position carbon of $1,3,4-$ thiadiazole), 169.1 (5-position carbon of 1,3,4-thiadiazole), 134.7-128.6 (aromatic carbon), $54.0\left(\mathrm{CH}_{3}\right)$, and 29.8-28.3 (aliphatic $\mathrm{CH}_{2}$ ) ppm.

1,7-Bis[5-(4-methoxycarbonylphenyl)-1,3,4-thiadiazol$2-y l]$ heptane $(4 a)$. The compound was synthesized from 1-chloroformyl-4-methoxycarbonylbenzene (1) and azelaic dihydrazide $(2 \mathrm{a})(m=7)$ according to the method for obtaining the bismethyl ester monomer (4b). Yield: 50\%; m.p.: K $159^{\circ} \mathrm{C} \mathrm{S} 195^{\circ} \mathrm{C}\left(\Delta H=62.0 \mathrm{KJ} \mathrm{mol}^{-1}\right) \mathrm{I}$.

$\mathrm{C}_{27} \mathrm{H}_{28} \mathrm{~N}_{4} \mathrm{O}_{4} \mathrm{~S}_{2}(536.7)$ Calc. C: $60.45 \%, \mathrm{H}: 5.22 \%, \mathrm{~N}$ : 10.45\%; Found C: $60.36 \%$, H: $5.20 \%$, N: $10.47 \%$.

Preparation of Polymers $(7 a-d)$ and $(8 a-c)$

A mixture of monomer $(4 \mathrm{a})(0.25 \mathrm{mmol}, 0.135 \mathrm{~g})$ and 1,10-decandiol $(5 \mathrm{c})(n=10)(0.30 \mathrm{mmol}, \quad 0.052 \mathrm{~g}) \quad$ was heated at $215-220^{\circ} \mathrm{C}$ for $2 \mathrm{~h}$ in the presence of a trace of tetraisopropyl orthotitanate as catalyst under nitrogen. The reaction system was heated at the same temperature for $30 \mathrm{~min}$. at $15-20$ Torr and for $30 \mathrm{~min}$ below 1 Torr. After polycondensation, the resulting solid was dissolved in TFAA and the solution was poured into methanol to reprecipitate the polymer $(7 \mathrm{c})$. The product was washed with water, refluxed with methanol three times and dried at $80^{\circ} \mathrm{C}$ for $24 \mathrm{~h}$ under reduced pressure. Yield: $85 \%$.

Polymers $(7 \mathrm{e}-\mathrm{h})$ and $(8 \mathrm{~d}-\mathrm{g})$ were synthesized in the same manner at $235-240^{\circ} \mathrm{C}$.

\section{Measurements}

FT-IR spectra were obtained on a Jasco FT/IR 5300 spectrometer by the $\mathrm{KBr}$ disk method. ${ }^{13} \mathrm{C}$ NMR spectra were recorded with a JEOL LMN EX270 spectrometer in TFAA(v)/CDCl ${ }_{3}(\mathrm{v})=3 / 1$. Differential scanning calorimetry (DSC) was carried out with a Shimadzu DSC-60 calorimeter at heating and cooling rates of $10^{\circ} \mathrm{C} \mathrm{min}{ }^{-1}$ under nitrogen. Peak maxima or steps were taken as phase transition temperatures. Optical textures of polymers were observed with a polarizing microscope (Nikon) equipped with a hot plate (magnification: $\times 200$ ). Numberaverage molecular weights $\left(\bar{M}_{n}\right)$ and molecular-weight distributions $\left(\bar{M}_{w} / \bar{M}_{n}\right)$ were estimated by size exclusion chromatography (SEC) with a Jasco 830-RI refractometer and column in combination (K-803/K-804)(Shodex), using polystyrene standard in chloroform as eluent. Temperature-dependent X-ray analysis was performed by a Rigaku Denki RINT 2500 generator equipped with a temperature controller with $\mathrm{Cu}-K_{\alpha}$ irradiation.

\section{RESULTS AND DISCUSSION}

\section{Synthesis of Monomers (4) and Polymers (7) and (8)}

Bismethyl ester monomers (4a) and (4b), $\alpha, \omega$-bis [5-(4methoxycarbonylphenyl)-1,3,4-thiadiazol-2-yl]alkane, were prepared by cyclodehydration of the corresponding intermediate bishydrazides (3) derived from 1-chloro-formyl4-methoxycarbonylbenzene (1) and azelaic (2a) or seba- 


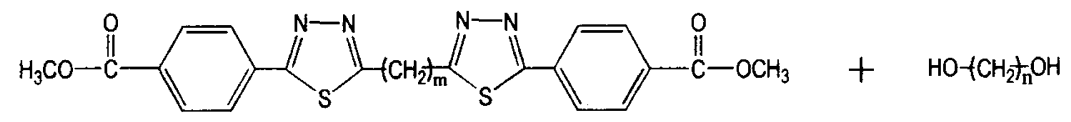

4

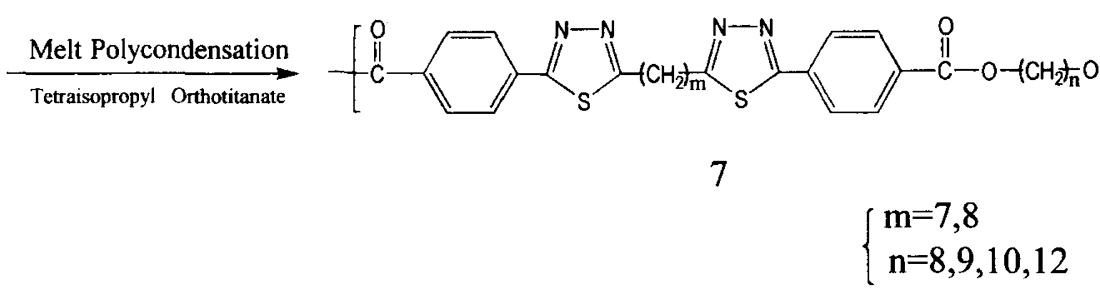

Scheme 2.

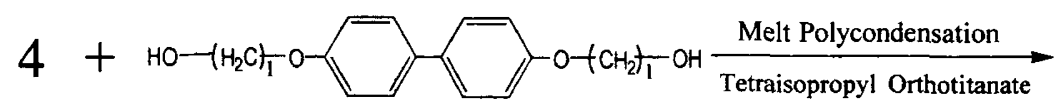

6



Scheme 3.

cic dihydrazide (2b) with Lawesson's reagent in 1,4dioxane as described previously ${ }^{16}$ (Scheme I). The bismethyl ester derivative (4a) with the heptamethylene chain formed enantiotropic smectic phase between $159^{\circ} \mathrm{C}$ and $195^{\circ} \mathrm{C}$, although the monomer $(4 \mathrm{~b})$ containing the octamethylene segment had no LC melts.

Semi-rigid polyesters (7) and (8), consisting of the twin biphenyl analogue of 1,3,4-thiadiazole (2-phenyl-1,3,4thiadiazole) having the hepta- or octamethylene segment in the central part were synthesized by melt polycondensation of the bismethyl ester monomers (4a) and (4b) with $\alpha, \omega$-alkylenediols (5) or $\omega, \omega^{\prime}$-(4,4'-biphenylenedioxy)dialcohols (6) in the presence of tetraisopropyl orthotitanate as catalyst (Schemes II and III). The polycondensation was carefully carried out as described in the experimental, because polymers from monomers (4) and a dioxydipentanol derivative of biphenyl began to decompose near polymerization temperatures and could not be obtained. Reaction proceeded easily to afford fibrous polymers $(7 \mathrm{a}-\mathrm{d})$ and $(7 \mathrm{~h})$, and light-brown colored powder polymers $(7 \mathrm{e}-\mathrm{g})$ and $(8 \mathrm{a}-\mathrm{g})$ at $67-95 \%$ yield. The preparation of these polymers (7) and (8) was confirmed by FT-IR and ${ }^{13} \mathrm{C}$ NMR spectra, and elemental analysis. The results are listed in Tables I and II. A typical ${ }^{13} \mathrm{C}$ NMR spectrum for polymer (8e) is shown in Figure 1. The data support the formation of the expected polyesters (7) and (8), although polymers (7e-g) had lower number-average molecular weights $\left(\bar{M}_{n}\right)$ of $8100-$ 13000 and wider molecular-weight distributions $\left(\bar{M}_{w} /\right.$ $\bar{M}_{n}$ ) of $3.39-5.48$ than the corresponding polyesters $(7 \mathrm{a}$ -d) and ( $7 \mathrm{~h})\left(\bar{M}_{n}=16300-25000, \bar{M}_{w} / \bar{M}_{n}=3.00-3.85\right)$ and the polyesters $(8 \mathrm{a}-\mathrm{g})$ containing the biphenyl unit $\left(\bar{M}_{n}=11500-18200, \bar{M}_{w} \bar{M}_{n}=2.65-3.33\right)$. As shown in Figure 1, the ${ }^{13} \mathrm{C}$ NMR spectrum for polymer (8e) in $\mathrm{CDCl}_{3}$ displayed carbon signals of ester $\mathrm{C}=\mathrm{O}$ at $171.1 \mathrm{ppm}$ and for 2 and 5 positions of 1,3,4-thiadiazole at 167.2 and $165.8 \mathrm{ppm}$ in addition to those for aromatic rings at $114.8-158.0 \mathrm{ppm}$, aliphatic chains at $25.9-$ $30.2 \mathrm{ppm}$ and $\mathrm{OCH}_{2}$ next to the ester group at $65.4 \mathrm{ppm}$. The other polymers $(7 \mathrm{a}-\mathrm{d}),(7 \mathrm{f}-\mathrm{h})$ and $(8 \mathrm{a}-\mathrm{g})$ showed similar ${ }^{13} \mathrm{C}$ NMR spectra. The FT-IR spectra of polymers (7) and (8) showed characteristic absorption bands for ester $\mathrm{C}=\mathrm{O}$ at $1716 \mathrm{~cm}^{-1}$ and 1,3,4-thiadiazole ring at $1402 \mathrm{~cm}^{-1}$, together with $\mathrm{C}-\mathrm{H}$ stretching bands at 2923 and $2851 \mathrm{~cm}^{-1}$, benzene ring $\mathrm{C}=\mathrm{C}$ stretching at 1608 $\mathrm{cm}^{-1}$ and $\mathrm{C}-\mathrm{O}-\mathrm{C}$ stretching at $1275 \mathrm{~cm}^{-1}$. Results of elemental analysis were in good agreement with those calculated. Polymers (7) and (8) were quite soluble in or- 
Table I. Results for polyester synthesis $(7 a-h)$

\begin{tabular}{|c|c|c|c|c|c|c|c|c|c|c|}
\hline \multicolumn{3}{|c|}{ Polymer } & \multirow{2}{*}{$\begin{array}{c}\text { Yield } \\
\%\end{array}$} & \multirow{2}{*}{$\bar{M}_{n}{ }^{a}$} & \multirow{2}{*}{$\bar{M}_{w} / \bar{M}_{n}{ }^{a}$} & \multirow{2}{*}{$\begin{array}{c}\text { Exp.formula } \\
\text { (form.weight) }\end{array}$} & \multicolumn{4}{|c|}{ Elemental analysis $/ \%$} \\
\hline No. & $\mathrm{m}$ & $\mathrm{n}$ & & & & & & $\mathrm{C}$ & $\mathrm{H}$ & $\mathrm{N}$ \\
\hline \multirow{2}{*}{$7 \mathrm{a}$} & \multirow{2}{*}{7} & \multirow{2}{*}{8} & \multirow{2}{*}{95} & \multirow{2}{*}{19500} & \multirow{2}{*}{3.00} & $\left(\mathrm{C}_{33} \mathrm{H}_{38} \mathrm{~N}_{4} \mathrm{O}_{4} \mathrm{~S}_{2}\right)_{\mathrm{k}}$ & Calc. & 64.08 & 6.15 & 9.06 \\
\hline & & & & & & $(618.8)_{k}$ & Found & 63.94 & 6.15 & 9.10 \\
\hline \multirow{2}{*}{$7 \mathrm{~b}$} & \multirow[b]{2}{*}{7} & \multirow{2}{*}{9} & \multirow{2}{*}{70} & \multirow{2}{*}{25000} & \multirow{2}{*}{3.23} & $\left(\mathrm{C}_{34} \mathrm{H}_{40} \mathrm{~N}_{4} \mathrm{O}_{4} \mathrm{~S}_{2}\right)_{\mathrm{k}}$ & Calc. & 64.56 & 6.33 & 8.86 \\
\hline & & & & & & $(632.8)_{\mathrm{k}}$ & Found & 64.33 & 6.40 & 8.71 \\
\hline \multirow{2}{*}{$7 \mathrm{c}$} & \multirow{2}{*}{7} & \multirow{2}{*}{10} & \multirow{2}{*}{85} & \multirow{2}{*}{24200} & \multirow{2}{*}{3.08} & $\left(\mathrm{C}_{35} \mathrm{H}_{42} \mathrm{~N}_{4} \mathrm{O}_{4} \mathrm{~S}_{2}\right)_{\mathrm{k}}$ & Calc. & 65.02 & 6.50 & 8.67 \\
\hline & & & & & & $(646.9)_{\mathrm{k}}$ & Found & 64.92 & 6.60 & 8.65 \\
\hline \multirow{2}{*}{$7 \mathrm{~d}$} & \multirow{2}{*}{7} & \multirow{2}{*}{12} & \multirow{2}{*}{83} & \multirow{2}{*}{16300} & \multirow{2}{*}{3.85} & $\left(\mathrm{C}_{37} \mathrm{H}_{46} \mathrm{~N}_{4} \mathrm{O}_{4} \mathrm{~S}_{2}\right)_{\mathrm{k}}$ & Calc. & 65.88 & 6.82 & 8.31 \\
\hline & & & & & & $(674.9)_{\mathrm{k}}$ & Found & 65.73 & 6.73 & 8.19 \\
\hline \multirow{2}{*}{$7 \mathrm{e}$} & \multirow{2}{*}{8} & \multirow{2}{*}{8} & \multirow{2}{*}{80} & \multirow{2}{*}{8100} & 5.48 & $\left(\mathrm{C}_{34} \mathrm{H}_{40} \mathrm{~N}_{4} \mathrm{O}_{4} \mathrm{~S}_{2}\right)_{\mathrm{k}}$ & Calc. & 64.56 & 6.33 & 8.86 \\
\hline & & & & & 0.48 & $(632.8)_{\mathrm{k}}$ & Found & 64.40 & 6.29 & 9.01 \\
\hline $7 f$ & 8 & 9 & 67 & 8100 & 339 & $\left(\mathrm{C}_{35} \mathrm{H}_{42} \mathrm{~N}_{4} \mathrm{O}_{4} \mathrm{~S}_{2}\right)_{\mathrm{k}}$ & Calc. & 65.02 & 6.50 & 8.67 \\
\hline$\pi$ & 8 & 9 & bi & 8100 & 0.35 & $(646.9)_{\mathrm{k}}$ & Found & 64.90 & 6.49 & 8.74 \\
\hline $7 \mathrm{~g}$ & 8 & 10 & 86 & 13000 & 4.93 & $\left(\mathrm{C}_{36} \mathrm{H}_{44} \mathrm{~N}_{4} \mathrm{O}_{4} \mathrm{~S}_{2}\right)_{\mathrm{k}}$ & Calc. & 65.45 & 6.67 & 8.48 \\
\hline & & & & & & $(660.9)_{\mathrm{k}}$ & Found & 65.42 & 6.58 & 8.45 \\
\hline $7 \mathrm{~h}$ & 8 & 12 & 80 & 23800 & 3.44 & $\left(\mathrm{C}_{38} \mathrm{H}_{48} \mathrm{~N}_{4} \mathrm{O}_{4} \mathrm{~S}_{2}\right)_{\mathrm{k}}$ & Calc. & 66.28 & 6.98 & 8.14 \\
\hline$\pi n$ & 0 & 12 & ou & 20000 & 0.44 & $(689.0)_{\mathrm{k}}$ & Found & 66.16 & 6.96 & 8.16 \\
\hline
\end{tabular}

${ }^{\mathrm{a}} \bar{M}_{n}$ : Number-average molecular weight, $\bar{M}_{w} / \bar{M}_{n}$ : Molecular-weight distribution measured by SEC using polystyrene standard in chloroform as eluent.

Table II. Results for polyester synthesis $(8 \mathrm{a}-\mathrm{g})$

\begin{tabular}{|c|c|c|c|c|c|c|c|c|c|c|}
\hline \multirow[b]{2}{*}{ No. } & \multirow{2}{*}{$\begin{array}{c}\text { Polymer } \\
\text { m }\end{array}$} & \multirow[b]{2}{*}{1} & \multirow{2}{*}{$\begin{array}{c}\text { Yield } \\
\%\end{array}$} & \multirow{2}{*}{$\bar{M}_{n}{ }^{\mathrm{a}}$} & \multirow{2}{*}{$\bar{M}_{w} / \bar{M}_{n}{ }^{\mathrm{a}}$} & \multirow{2}{*}{$\begin{array}{c}\text { Exp.formula } \\
\text { (form.weight) }\end{array}$} & \multicolumn{4}{|c|}{ Elemental analysis/\% } \\
\hline & & & & & & & & $\mathrm{C}$ & $\mathrm{H}$ & $\mathrm{N}$ \\
\hline \multirow{2}{*}{$8 \mathrm{a}$} & \multirow{2}{*}{7} & \multirow{2}{*}{8} & \multirow[t]{2}{*}{80} & \multirow[t]{2}{*}{15300} & \multirow[t]{2}{*}{3.13} & \multirow{4}{*}{$\begin{array}{c}\left(\mathrm{C}_{53} \mathrm{H}_{62} \mathrm{~N}_{4} \mathrm{O}_{6} \mathrm{~S}_{2}\right)_{\mathrm{k}} \\
(915.2)_{\mathrm{k}} \\
\left(\mathrm{C}_{57} \mathrm{H}_{70} \mathrm{~N}_{4} \mathrm{O}_{6} \mathrm{~S}_{2}\right)_{\mathrm{k}} \\
(971.3)_{\mathrm{k}}\end{array}$} & Calc. & 69.58 & 6.78 & 6.13 \\
\hline & & & & & & & Found & 68.57 & 6.86 & 5.73 \\
\hline \multirow{2}{*}{$8 \mathrm{~b}$} & \multirow{2}{*}{7} & \multirow{2}{*}{10} & \multirow[t]{2}{*}{93} & \multirow[t]{2}{*}{11500} & \multirow[t]{2}{*}{3.33} & & Calc. & 70.52 & 7.22 & 5.77 \\
\hline & & & & & & & Found & 69.97 & 7.27 & 5.06 \\
\hline \multirow{2}{*}{$8 c$} & \multirow{2}{*}{7} & \multirow{2}{*}{11} & \multirow[t]{2}{*}{89} & \multirow[t]{2}{*}{12800} & \multirow[t]{2}{*}{2.65} & \multirow{2}{*}{$\begin{array}{c}\left(\mathrm{C}_{59} \mathrm{H}_{74} \mathrm{~N}_{4} \mathrm{O}_{6} \mathrm{~S}_{2}\right)_{\mathrm{k}} \\
(999.4)_{\mathrm{k}}\end{array}$} & Calc. & 70.94 & 7.41 & 5.61 \\
\hline & & & & & & & Found & 70.00 & 7.30 & 5.90 \\
\hline \multirow{2}{*}{$8 \mathrm{~d}$} & \multirow{2}{*}{8} & \multirow{2}{*}{6} & \multirow[t]{2}{*}{86} & \multirow[t]{2}{*}{17800} & \multirow[t]{2}{*}{2.72} & \multirow{4}{*}{$\begin{array}{c}\left(\mathrm{C}_{50} \mathrm{H}_{56} \mathrm{~N}_{4} \mathrm{O}_{6} \mathrm{~S}_{2}\right)_{\mathrm{k}} \\
(873.2)_{\mathrm{k}} \\
\left(\mathrm{C}_{54} \mathrm{H}_{64} \mathrm{~N}_{4} \mathrm{O}_{6} \mathrm{~S}_{2}\right)_{\mathrm{k}} \\
(929.3)_{\mathrm{k}}\end{array}$} & Calc. & 68.81 & 6.42 & 6.42 \\
\hline & & & & & & & Found & 67.65 & 6.34 & 6.11 \\
\hline \multirow{2}{*}{$8 \mathrm{e}$} & 8 & 8 & 89 & 18200 & 2.99 & & Calc. & 69.83 & 6.90 & 6.03 \\
\hline & 8 & 8 & & & & & Found & 69.58 & 6.91 & 5.37 \\
\hline & 8 & 10 & 93 & 12800 & 2.95 & $\left(\mathrm{C}_{58} \mathrm{H}_{72} \mathrm{~N}_{4} \mathrm{O}_{6} \mathrm{~S}_{2}\right)_{\mathrm{k}}$ & Calc. & 70.73 & 7.12 & 5.69 \\
\hline $8 \mathrm{t}$ & 8 & 10 & & & & $(985.4)_{\mathrm{k}}$ & Found & 70.47 & 7.31 & 5.07 \\
\hline & & & 91 & 13500 & 2.91 & $\left(\mathrm{C}_{60} \mathrm{H}_{76} \mathrm{~N}_{4} \mathrm{O}_{6} \mathrm{~S}_{2}\right)_{\mathrm{k}}$ & Calc. & 71.15 & 7.51 & 5.53 \\
\hline $8 \mathrm{~g}$ & 8 & 11 & & & & $(1013)_{\mathrm{k}}$ & Found & 70.01 & 7.54 & 5.01 \\
\hline
\end{tabular}

${ }^{a} \bar{M}_{n}$ : Number-average molecular weight, $\bar{M}_{w} / \bar{M}_{n}$ : Molecular-weight distribution measured by SEC using polystyrene standard in chloroform as eluent.

ganic solvents such as chloroform and TFAA, and gave flexible $(7 \mathrm{a}-\mathrm{d}$ and $7 \mathrm{~h})$ or brittle $(7 \mathrm{e}-\mathrm{g}$ and $8 \mathrm{a}-\mathrm{g})$ films cast from chloroform solution.

Thermal and Mesogenic Properties of Polymers (7) and (8)

Semi-rigid polyesters based on twin biphenyl analogue of 1,3,4-thiadiazole having central decamethylene segment show thermotropic nematic and smectic phases, ${ }^{16}$ but LC temperature range is narrow. In this paper, the LC properties of polyesters (7) and (8) were evaluated by DSC, polarizing microscope equipped with a hot stage, miscibility test and temperature-dependent $\mathrm{X}$-ray analysis.

DSC curves of polymers (7) in Figure 2 showed one or two endothermal peaks due to melting $\left(T_{\mathrm{m}}\right)$ and solid-tosolid transitions $\left(T_{\mathrm{k}}\right)$, together with glass transition steps $\left(T_{\mathrm{g}}\right)$ on the first and second heating scans. Only polymer (7a) exhibited isotropization transition $\left(T_{\mathrm{i}}\right)$ at $207^{\circ} \mathrm{C}$ in addition to $T_{\mathrm{k}}$ at $187^{\circ} \mathrm{C}$ and $T_{\mathrm{m}}$ transitions at $200^{\circ} \mathrm{C}$. On the first and second cooling runs, polymers $(7 \mathrm{~b}-\mathrm{h})$ except for the polymer $(7 \mathrm{a})$ showed two or three exotherms due to isotropization-to- $\mathrm{LC}$ phase $\left(T_{\mathrm{i}}\right)$ at $171{ }^{\circ} \mathrm{C}-206^{\circ} \mathrm{C}$, LC phase-to-crystallization $\left(T_{\mathrm{c}}\right)$ at $146^{\circ} \mathrm{C}$ $-196^{\circ} \mathrm{C}$, which corresponds to $T_{\mathrm{m}}$ on the heating scans and $T_{\mathrm{k}}$ transitions at $175^{\circ} \mathrm{C}-180^{\circ} \mathrm{C}$, and formed the monotropic LC phase between $T_{\mathrm{c}}$ and $T_{\mathrm{i}}$. Polarizing microscope observation of textures indicated the polymer (7a) to form the enantiotropic nematic phase between $T_{\mathrm{m}}$ at $200^{\circ} \mathrm{C}$ (or $T_{\mathrm{c}}$ at $167^{\circ} \mathrm{C}$ on cooling) and $T_{\mathrm{i}}$ at $207^{\circ} \mathrm{C}$ (at $200^{\circ} \mathrm{C}$ on cooling), and polymers $(7 \mathrm{~b}-\mathrm{h})$ the monotropic nematic phase at the LC temperature $\left(\Delta T=T_{\mathrm{i}}-T_{\mathrm{c}}\right)$. Miscibility tests using 2,5-bis(4-methoxyphenyl)-1,3,4thiadiazole ${ }^{2}$ and the temperature-dependent X-ray analysis, in which broad reflections around $2 \Theta=22^{\circ}$ and no reflections at small angles were observed at LC temperature on the heating and the cooling scans, support the formation of the nematic phase in the polyesters (7).

The thermal and mesogenic behavior of polymers (8) containing the biphenyl moiety considerably differed from that for polymers (7) (Figure 3). Polyesters $(8 a-c)$ based on the twin analogue linked to heptamethylene chain had normal melting temperatures. Among polymers $(8 \mathrm{~d}-\mathrm{g})$ based on the twin compounds having octamethylene segment, most polymers ( $8 \mathrm{~d}$, e, and $\mathrm{g}$ ) showed endothermal peaks due to $T_{\mathrm{k}} \mathrm{s}$ and $T_{\mathrm{m}} \mathrm{s}$ on the heating scans and exotherms attributed to $T_{\mathrm{i}}$ and $T_{\mathrm{c}}$ transitions on the cooling runs, as recognized by misci- 

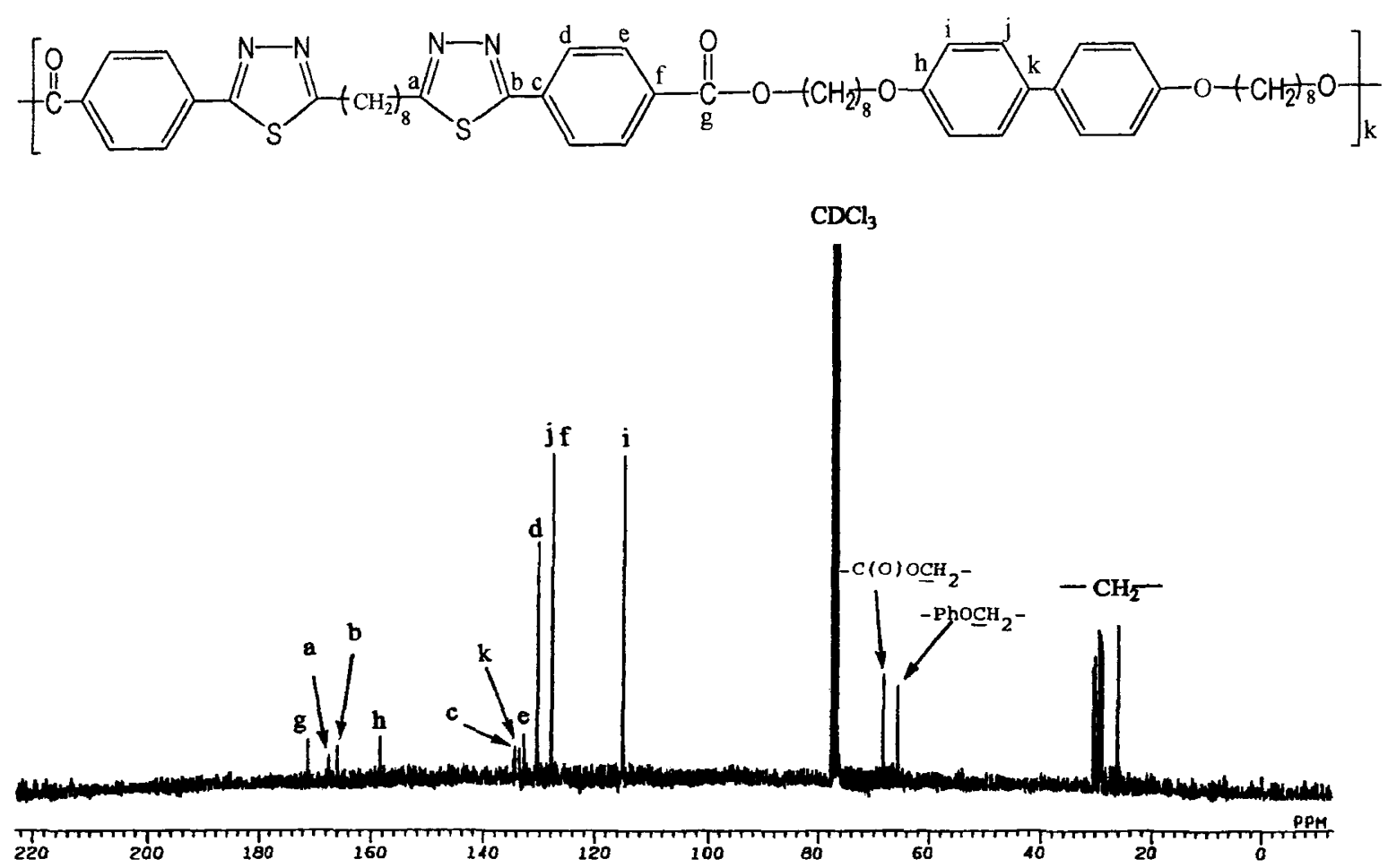

Figure 1. ${ }^{13} \mathrm{C} \mathrm{NMR}$ spectrum for polymer (8e) in $\mathrm{CDCl}_{3}$.

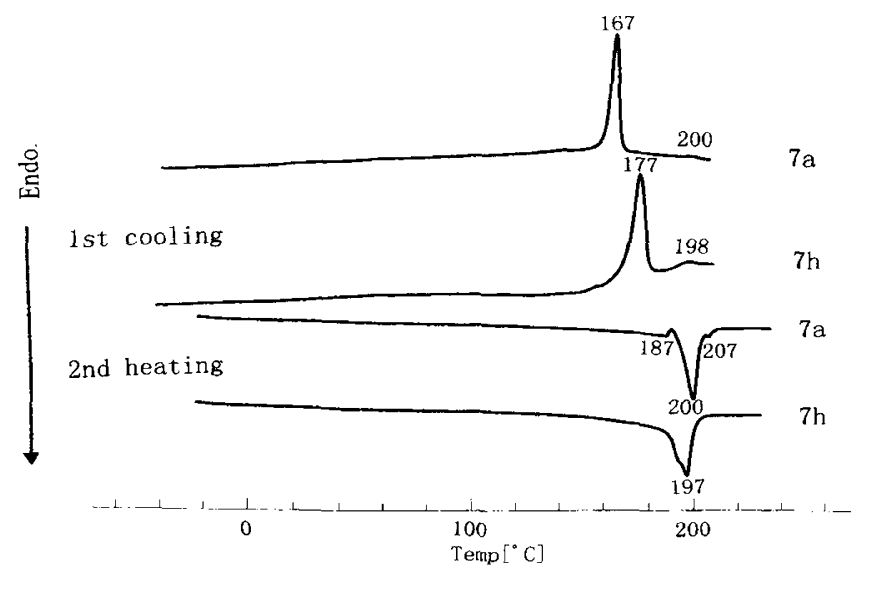

Figure 2. DSC curves for polymers (7a) and (7h) on the first cooling and second heating.

bility tests and temperature-dependent X-ray analysis indicating the monotropic nematic phase to emerge in these polymers as observed in the polyesters $(7 a-h)$. Polymer (8f) had no LC melt. The polarizing microphotograph for polymer (8d) at $193^{\circ} \mathrm{C}$ in the cooling run is shown in Figure 4. Polymers (7) derived from $\alpha, \omega$ alkylenediols (5) formed the nematic phase independent of length of aliphatic spacers ( $m=7,8$ and $n=8,9,10,12)$ in the repeating unit, but for polymers (8) containing the biphenyl unit, polymers $(8 \mathrm{a}-\mathrm{c})$ and $(8 \mathrm{f})$ had no LC phase in spite of the presence of the well-known biphenyl mesogen in the backbone despite our expecta-

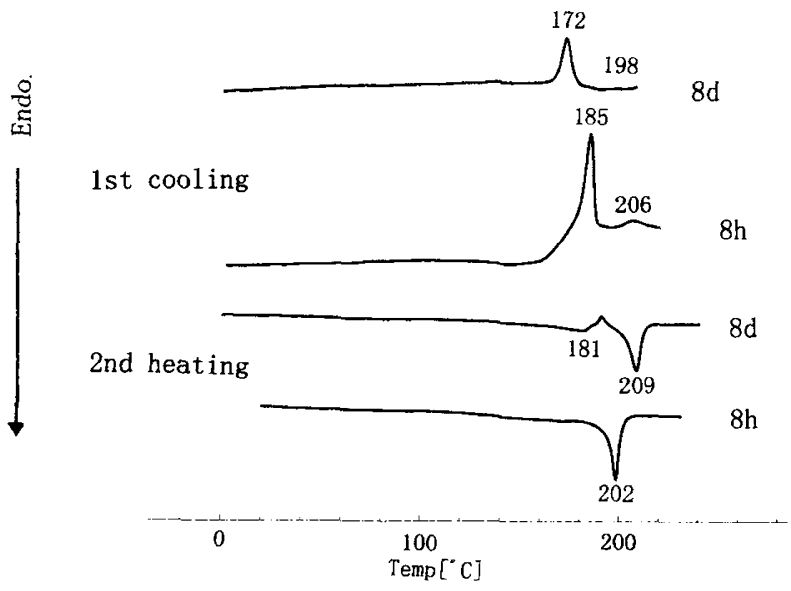

Figure 3. DSC curves for polymers ( $8 d$ ) and ( $8 h$ ) on the first cooling and second heating.

tion. Polyesters $\left(7 \mathrm{e}^{-\mathrm{h}} \mathrm{h}\right)$ and $(8 \mathrm{~d}-\mathrm{g})$ based on the twin biphenyl analogue with the octamethylene chain in the central part showed the nematic phase and possessed higher transition temperatures than polymers $(7 \mathrm{a}-\mathrm{d})$ and $(8 \mathrm{a}-\mathrm{c})$ having the central heptamethylene segment. Polyesters (7) and (8) in the present work had higher isotropization temperatures $\left(T_{\mathrm{i}}\right)$ and wider LC temperature range $(\Delta T)$ than previously reported for analogous polyesters. ${ }^{16}$ Phase transition temperatures for polyesters (7) and (8) are listed in Tables III and IV, respectively.

Polymers (7) without the biphenyl unit would thus 
Table III. Phase transition data for polyesters $(7 \mathrm{a}-\mathrm{h})^{\mathrm{a}}$

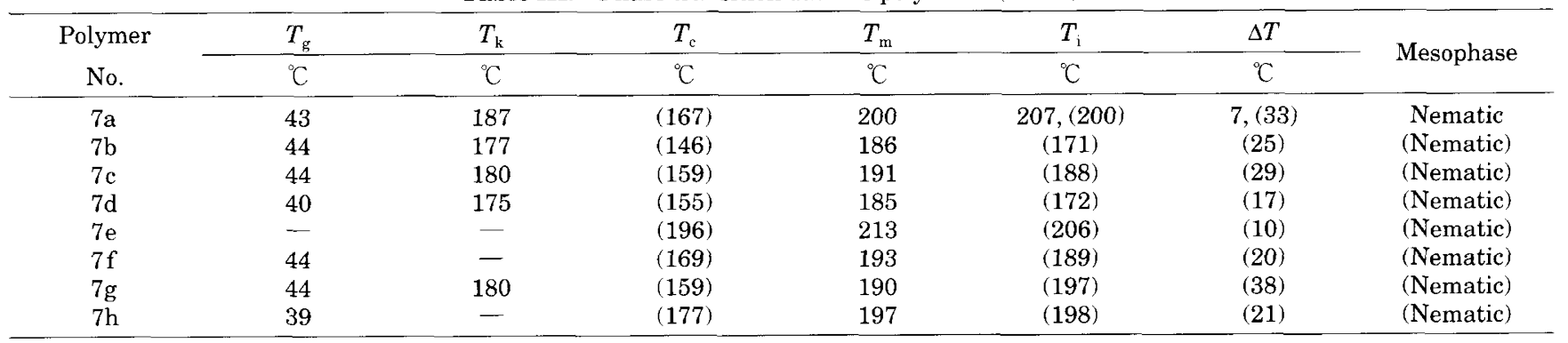

${ }^{a}$ First cooling data in parentheses. $T_{\mathrm{i}}$ : isotropization temperature, $T_{\mathrm{m}}$ : melting temperature, $T_{\mathrm{c}}$ : crystallization temperature, $T_{\mathrm{k}}$ : solid-tosolid transition temperature, $T_{\mathrm{g}}$ : glass transition temperature, $\Delta T=T_{\mathrm{i}}-T_{\mathrm{c}}$ and $T_{\mathrm{i}}-T_{\mathrm{m}}$ : LC temperature range.

Table IV. Phase transition data for polyesters $(8 \mathrm{a}-\mathrm{g})^{\mathrm{a}}$

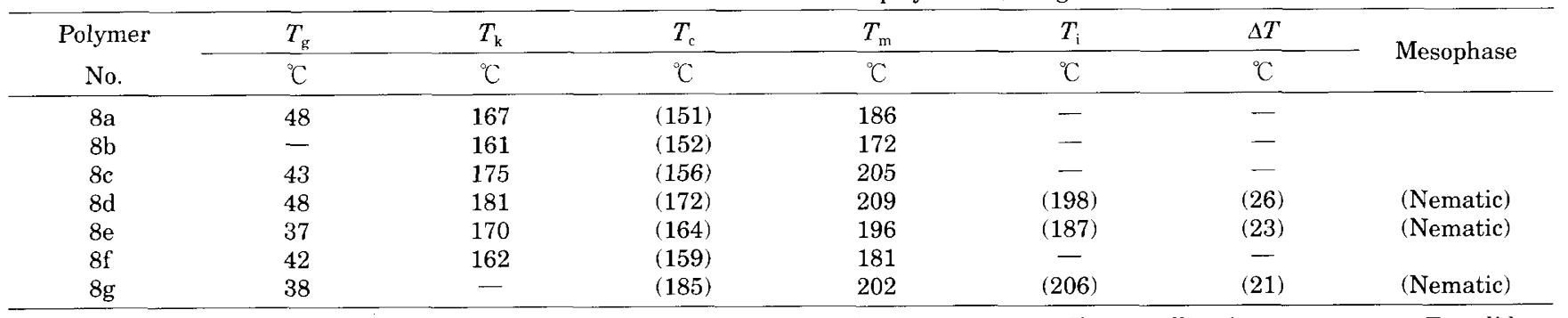

${ }^{a}$ First cooling data in parentheses. $T_{\mathrm{i}}$ : isotropization temperature, $T_{\mathrm{m}}$ : melting temperature, $T_{\mathrm{c}}$ : crystallization temperature, $T_{\mathrm{k}}$ : solid-tosolid transition temperature, $T_{\mathrm{g}}$ : glass transition temperature, $\Delta T=T_{\mathrm{i}}-T_{\mathrm{c}}$ : LC temperature range.

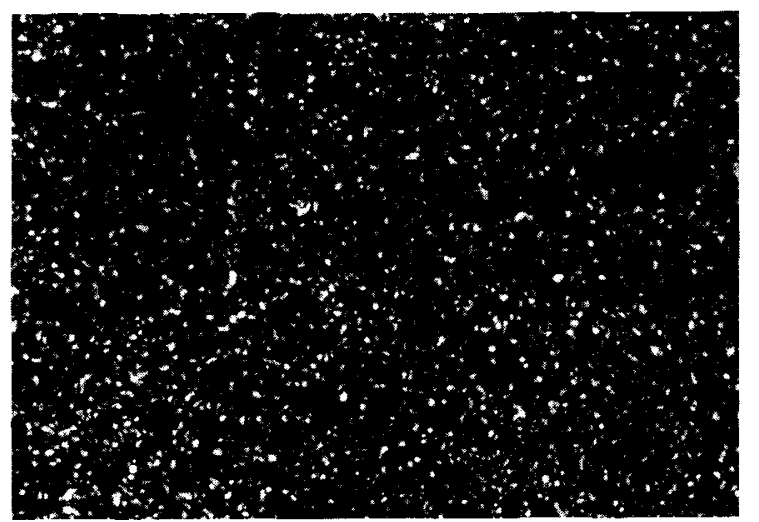

Figure 4. Polarizing microphotograph of polymer (8d) at $193^{\circ} \mathrm{C}$ on the first cooling (magnification: $\times 200$ ).

likely form the thermotropic nematic phase compared with polymers (8) with the biphenyl mesogen, although LC temperature range was narrow. Introduction of the biphenyl moiety, a mesogen different from the 2-phenyl1,3,4-thiadiazole, into the polymer backbones would disturb the orientation of polymer chains and prevent LC formation in the semi-rigid polyesters composed of the twin five-membered heterocyclic moiety as mesogen and this would explain the above. A combination of an odd number spacer $(m=7)$ between the biphenyl analogues with the well-known biphenyl unit in backbone seems to work negatively in LC formation for these polymers. The mesogenic quality of twin biphenyl analogues of the 1,3,4-thiadiazole (2-phenyl-1,3,4-thiadiazoles) in this work is less than that of previously-mentioned terphenyl analogues of 1,3,4-thiadiazole (2,5-diphenyl-1,3,4-thiadiazoles), ${ }^{1-5}$ as expected.

Acknowledgment. The authors thank Ms. M. Egawa for conducting the elemental analysis.

\section{REFERENCES}

1. A. Greiner and H.-W. Schmidt, "Handbook of Liquid Crystals," Vol. 3, D. Demus, J. Goodby, G. W. Gray, H.-W. Spiess, and V. Vill, Ed., Wiley-VCH publishers, Weinheim, 1998, p 3.

2. K. Dimitrowa, J. Hauschild, H. Zaschke, and H. Schubert, J. Prakt. Chem., 322, 933 (1980).

3. W. Schafer, U. Rosenfeld, H. Zaschke, H. Stettin, and H. Kresse, J. Prakt. Chem., 331, 4 (1989).

4. C. Tschierske, H. Zaschke, H. Kresse, A. Madicke, D. Demus, D. Girdziunaite, and G. Y. Bak, Mol. Cryst. Liq. Cryst., 191, 223 (1990).

5. M. Sato and S. Ujiie, Adv. Mater., 8, 567 (1996).

6. M. Sato, K. Nakadera, and K. Mukaida, Makromol. Chem., Rapid Commun., 13, 427 (1992).

7. M. Sato, T. Kamita, K. Nakadera, and K. Mukaida, Eur. Polym. J., 31, 395 (1995)

8. M. Sato and S. Takeuchi, Kobunshi Ronbunshu, 56, 260 (1999).

9. J. Lee, S. I. Hong, and S. S. Hwang, Macromol. Chem. Phys., 198, 391 (1997).

10. G. Girdziunaite, C. Tschierske, E. Novotona, H. Kresse, and A. Hetzheim, Liq. Cryst., 10, 397 (1991).

11. N. K. Chudgar, S. N. Shah, and R. A. Vova, Mol. Cryst. Liq. Cryst., 172, 51 (1989).

12. A. A. El-Azhary, Spectrochim. Acta, Part A, 52, 33 (1996).

13. M. Sato, S. Takeuchi, and R. Hino, Macromol. Rapid Commun., 20, 373 (1999).

14. K. Zab, O. Agert, D. Joachimi, B. Neumann, and C. Tschierske, Liq. Cryst., 18, 489 (1995).

15. K. Zab, D. Joachimi, E. Novotona, S. Diele, and C. Tschierske, 


\section{Thermotropic Liquid-Crystalline Polymers}

Liq. Cryst., 18, 631 (1995).

16. M. Sato, Macromol. Rapid Commun., 20, 77 (1999).

17. M. Sato, K. Nakatsuchi, and Y. Ohkatsu, Makromol. Chem., Rapid Commun., 7, 231 (1986).

18. M. Sato, K. Kurosawa, K. Nakatsuchi, and Y. Ohkatsu, J. Polym. Sci., Part A: Polym. Chem., 26, 3077 (1988).
19. M. Ando and T. Uryu, J. Polym. Sci., Part A: Polym. Chem., 28, 2575 (1990).

20. J.-B. Lee, T. Kato, T. Yoshida, and T. Uryu, Macromolecules, 26, 4989 (1993).

21. D.-J. Lee, J.-B. Lee, N. Koide, E. Akiyama, and T. Uryu, Macromolecules, 31, 975 (1998). 